\title{
ENRIQUE BRUNIARD, UNA VIDA DEDICADA A LA GEOGRAFÍA
}

\author{
Life dedicated to Geography. Enrique Bruniard
}

\section{Liliana Ramírez ${ }^{1}$}

Recibido: 10/01/2018 //Aceptado: 10/02/2018

Enrique Danilo Bruniard nació el 4 de julio de 1935 en Santo Tomé, Santa Fe, y como tantos santafesinos se atrevió al Chaco en la mitad del siglo pasado, exactamente en marzo de 1960. Coraje, tenacidad y templanza se necesitaban tener en esa época para animarse a conquistar una provincia recientemente creada que se encontraba en pleno proceso de conformación de sus instituciones. La Universidad Nacional del Nordeste creada en 1956, y las Escuelas y Facultades que la constituían, era una de esas instituciones que requería de profesionales que se radicaran y que se comprometieran con la organización inicial. Enrique Bruniard fue uno de ellos, se había recibido en el Instituto Nacional del Profesorado de Paraná y cuando llegó al Chaco, convocado por el profesor Carlos Álvarez que había sido director de la carrera de Geografía en aquel instituto, tenía tan solo 25 años, se sumó así a los profesores fundacionales, promotores e impulsores de las actividades propias de una Facultad que iniciaba su camino y en la que todo estaba por hacerse.

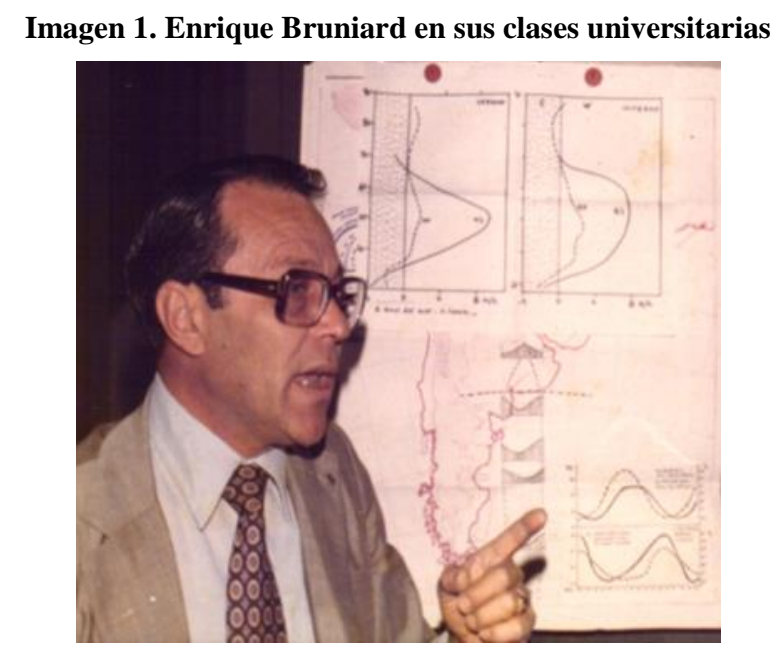

\section{Conociendo al docente}

Es imposible hablar de Geografía en el Chaco y en la Argentina sin mencionar la excelente labor que desarrolló el Dr. Bruniard en la UNNE, su tarea fue incesante desde el mismo momento en que se sumó al

\footnotetext{
${ }^{1}$ Dra. en Geografía. Vicedecana de la Facultad de Humanidades, Universidad Nacional del Nordeste. Investigadora IndependienteIIDTHH-CONICET-UNNE. 1ramirez@hum.unne.edu.ar
} 
plantel docente de profesores fundacionales. Los primeros años los dedicó a colaborar en la organización del Departamento y en la mejora del plan de estudios del Profesorado en Geografía; se ocupó de elaborar el diseño curricular, inicialmente de tres años, que requería, por un lado, la inclusión de materias y, por otro, ampliarlo a cuatro años, fueron necesarias numerosas jornadas de trabajo durante las cuales se planificó una nueva propuesta de plan, pero éste tenía que ser acompañado por tentadores formatos de trabajo para que docentes de otras provincias se sientan seducidos por las propuestas y decidieran venir al Chaco. En este contexto las ideas, los aportes y los planteamientos del profesor Bruniard fueron fundamentales para dar origen al plan de estudios que finalmente se implementó en 1962. A partir de ese momento tuvo a su cargo la asignatura "Climatología", esta materia fue su pasión lo vinculó a la docencia por 50 años.

Cursar Climatología con Bruniard significaba un antes y un después en el conocimiento de lo que un docente prodiga en una clase. Prefería el horario de las quince, cinco minutos antes de la hora acordada estaba en el aula, siempre de corbata, de preferencia corbata roja y camisa blanca, tal vez, quien sabe, debido a su ferviente fanatismo hacia los "millonarios" de Núñez. Este atuendo simbolizaba, imagino, el respeto por la labor docente, el respeto por sus alumnos, el respeto por la universidad y, seguramente, la herencia de los años iniciales en los que la formalidad en la vestimenta dominaba el escenario de la Facultad sea cual fuera la circunstancia. Llegaba al aula acompañado de sus láminas prolijamente elaboradas. En una época en que las diapositivas eran escasas, no existían los power point y mucho menos los videos de los que hoy disponemos en internet, esas láminas eran recursos didácticos innovadores con un alto poder de entendimiento que lograban cautivar a los cursantes. Sus clases se caracterizaban por la excelencia: vocabulario y términos apropiados, sin ambigüedad, inequívocos, entendibles; contenidos significativos, relevantes, actualizados, indagados en profundidad; pertinencia didáctica con recursos y estrategias que impedían que la mente divague. Así lograba mantener la atención de los estudiantes durante todo el tiempo que durara la clase y siempre conseguía que uno se quedara con sabor a más, como una historia o un relato que ansiábamos continuar al día siguiente. Esta excelencia, sumada al entusiasmo y a la dedicación que le imprimía a sus clases y que se apreciaba explícitamente cada día, generaba admiración en quienes cursábamos, en silencio y con mucha reserva -estoy segura- todos queríamos imitarlo, ser él en alguna medida.

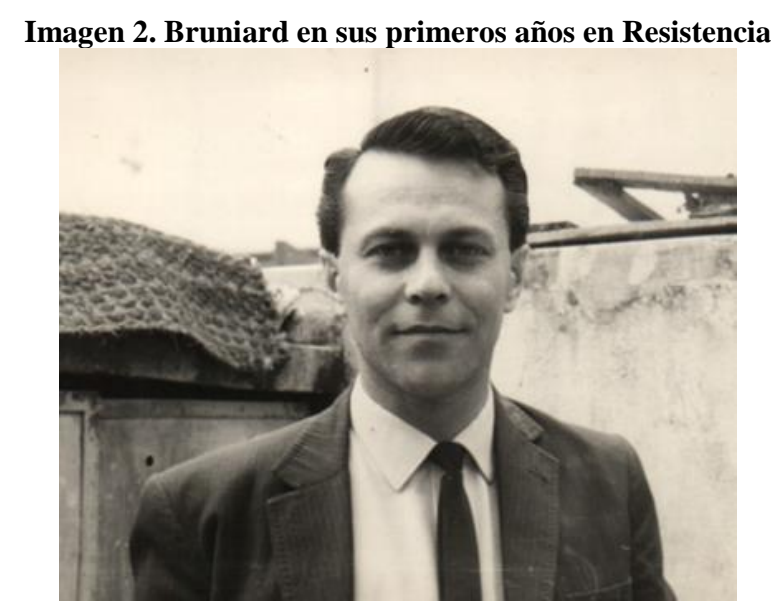




\section{Conociendo al investigador}

Después de los primeros años de su vida académica en la Facultad de Humanidades en que los esfuerzos se volcaron a completar el plantel docente y a implementar un plan de estudios necesario para la región, las energías se encaminaron a producir conocimientos. Bruniard sostenía que era muy difícil la enseñanza de la Geografía si primero no se generan datos, información y conocimiento del lugar en el que estamos emplazados.

El final de la década de los años '60 lo encontró sembrando las primeras semillas de lo que fue una amplia y exitosa trayectoria en investigación. El 9 de marzo de 1967 se creó Gabinete de Geografía y el 22 de marzo del año 1967 el profesor Bruniard fue designado director del mismo. En varias ocasiones sus propios relatos nos permitieron conocer los acontecimientos y factores que rondaron la creación del Gabinete. El primer factor, a juicio del propio Bruniard, tuvo que ver con un contexto institucional que comenzó a normalizarse en 1964 ya que se dispuso la convocatoria de los primeros concursos de profesores y de esta forma el régimen de contratos anuales fue sustituido paulatinamente por las dedicaciones exclusivas, situación que permitió que el núcleo inicial de profesores venidos desde otras provincias se afincara definitivamente en Resistencia. En paralelo a este contexto institucional, las actividades de la Facultad iban creciendo, se necesitaban más espacios físicos para albergarlas y los docentes, que a su llegada desde otras provincias residían en el mismo edificio de la Facultad, paulatinamente comenzaron a abandonar estas instalaciones para concretar sus proyectos personales y familiares. Por otro lado, mientras los docentes con dedicación exclusiva residieron en el edificio de la Facultad no fue necesario disponer de un espacio de trabajo ya que stricto sensu "vivían en el lugar de trabajo"; sin embargo, en la medida en que se iba concretando su residencia en otras viviendas de la ciudad, comenzaron a requerir espacios para cumplir la carga horaria correspondiente a la dedicación exclusiva y concretar así sus labores cotidianas, fue necesario disponer de espacios en condiciones adecuadas tanto para desarrollar las actividades de investigación como para disponer y resguardar de los recursos bibliográficos, cartográficos, documentales necesarios para tal fin.

A la circunstancia de coyuntura institucional comentada antes, mezclada con razones de índole personal de los docentes, se le sumó el interés de algunos de ellos por incrementar, ahondar e incentivar entre sus colegas la labor investigativa, interés que fue propiciado además por vínculo natural que comenzaron a tener con colegas de otras universidades. En el caso particular de Geografía, dos sucesos de la vida personal del Dr. Bruniard fueron cómplices necesarios para incrementar el interés. En primer lugar, en 1962, realizó una visita al Departamento de Geografía de la Universidad Nacional de Cuyo en cuyas instalaciones ya funcionaba el Instituto, ello significó un acercamiento inicial a las funciones que se desarrollaban en ese lugar. Esta estancia y los vínculos logrados con los colegas de aquella región fueron el puntapié para lograr una invitación a la Universidad de Burdeos donde realizó un larga y provechosa estadía, este segundo suceso que correspondió a los años 1964 y 1965, le permitieron tener una mayor proximidad a las disímiles y enri- 
quecedoras actividades de investigación que se allí realizaban y, aunque el Dr. Bruniard no lo aceptaba conscientemente, seguramente la imagen de los institutos de investigación que tuvo oportunidad de conocer en Mendoza y en Burdeos fue un factor determinante para que él promoviera su creación en la Facultad de Humanidades de la UNNE.

Fue así que el final de la década del '60 lo encontró al frente del Gabinete de Geografía, luego Instituto, encabezando un proyecto que estuvo financiado por el entonces organismo de ciencia y tecnología de la nación y que le permitió, junto a un equipo de colegas, realizar el primer relevamiento de la población, hábitat y servicios de lo que hoy es el área metropolitana del Gran Resistencia. Este proyecto no fue algo común para la época, fue un trabajo significativamente innovador ya que incluyó la obtención de fotografías de alta resolución desde un avión o plataforma aérea. En los mismos tiempos en que a nivel mundial se estaban lanzando los primeros satélites Landsat, el Dr. Bruniard y su equipo, en el Chaco, lograban fotografiar al área metropolitana con imágenes de alta calidad. Los resultados de este proyecto dieron el puntapié inicial de la Revista Geográfica que todavía hoy perdura en su formato de Atlas. Tanto la Revista como el Atlas dan cuenta de sus aptitudes y condiciones para conducir equipos de investigación, los años setenta, ochenta y noventa lo encontraron dirigiendo grupos, fueron las décadas en que se dieron a conocer los cuatro volúmenes de la Revista Geográfica y la primera época de los Atlas de Chaco y de Corrientes. Nos dirigió, acompañó, formó y aconsejó en variadas ocasiones y circunstancias, tantas que resulta difícil hacer una síntesis. Esencialmente era una persona que enseñaba, transmitía y conducía, en primer lugar con el ejemplo cotidiano; también podía hacer observaciones "al pasar" que entendíamos al momento dado que su sutiliza para comentarlas calaban profundamente en nosotros; y, claro, también, en las correcciones de los manuscritos que le presentábamos.

Imagen 3. Bruniard recibiendo el premio Juan José Biedma

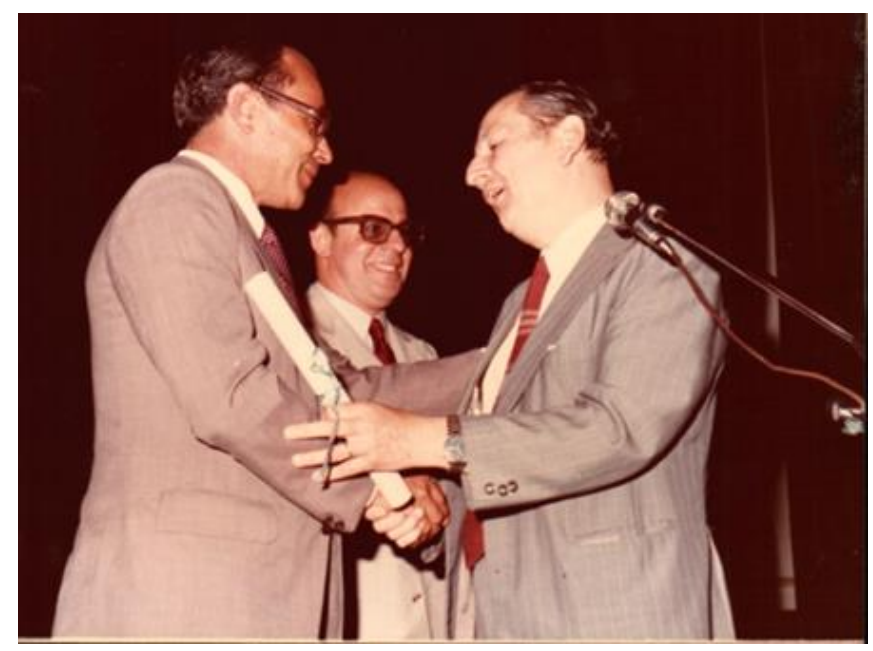

Su labor como mentor de equipos y grupos de investigación no impidió que también avanzara en producciones individuales. La Revista Geográfica No 4, El Gran Chaco Argentino (1979), mereció el premio Juan José Biedma de la Sociedad Argentina de Estudios Geográficos en 1981. Artículos y colecciones se 
sumaban de forma permanente a estas producciones de envergadura. En 1982 defendió su tesis doctoral en la Universidad Nacional de Cuyo y la trascendencia y calidad de la misma le significaron su ingreso a la Academia Nacional de Geografía en 1990. Años después, en 1995, la publicación de su tesis doctoral sobre El clima de las planicies del norte argentino, fue distinguida con el Premio Perito Moreno también de la Sociedad Argentina de Estudios Geográficos.

El final del siglo XX y los cambios institucionales profundizaron, ahondaron y exhibieron su incesante crecimiento como investigador. La editorial de la UNNE cuenta en su catálogo de publicaciones con sus tres últimos libros "Geografía de los Climas y de las Formaciones Vegetales" (1996), "Los regímenes hídricos de las formaciones vegetales: Aportes para un modelo fitoclimático mundial" (1999) y "Clima, Paisaje y Geografía" (2004).

De la misma manera que su imagen como docente nos deslumbraba en sus clases, su conducta como investigador también nos asombraba. Cada día de los años que me tocó compartir con él en el Instituto de Geografía, e imagino que los años que no compartí también, era el primero en llegar. Antes de las 7 de la mañana ya estaba sentado en su mesa de trabajo, sólo se levantaba un par de veces, una a calentar el agua para el mate, la otra para conversar unos pocos minutos en el espacio común que se compartía. Minutos antes de las 12 , invariablemente, se retiraba para almorzar y mirar el "informativo" -le fascinaba estar bien informado- y casi siempre se iba diciendo "ya es la hora en que el sol la cresta dora". Antes de las 15 volvía al Instituto. La siesta reparadora le permitía volver al trabajo otras cuatro horas que, sumadas a las cinco que ya había cumplido en la mañana, completaban nueve horas de diaria labor de investigación. No recuerdo ausencia al trabajo. Admirable.

\section{Conociendo a la persona}

Es difícil destacar a la persona de una forma acabada, ya que fue un ser humano colmado de un, ya que su prestancia, su caballerosidad, su generosidad y solidaridad

En el año 2007 se cumplieron 40 años del Instituto de Geografía y tuvimos oportunidad de homenajear al Dr. Bruniard entregándole una placa en reconocimiento a su trayectoria.

Fue un momento muy especial para todos. Éramos conscientes que se trataba de sus últimos años en la Facultad. Sabíamos que pronto tomaría la decisión de alejarse definitivamente de la Institución a la que le brindó toda una vida de vocación, esmero y compromiso. El departamento y el instituto de Geografía fueron sus espacios naturales, docente e investigador por esencia, pero también fue consejero directivo y ocupó numerosos cargos de gestión hasta llegar a ser decano. 


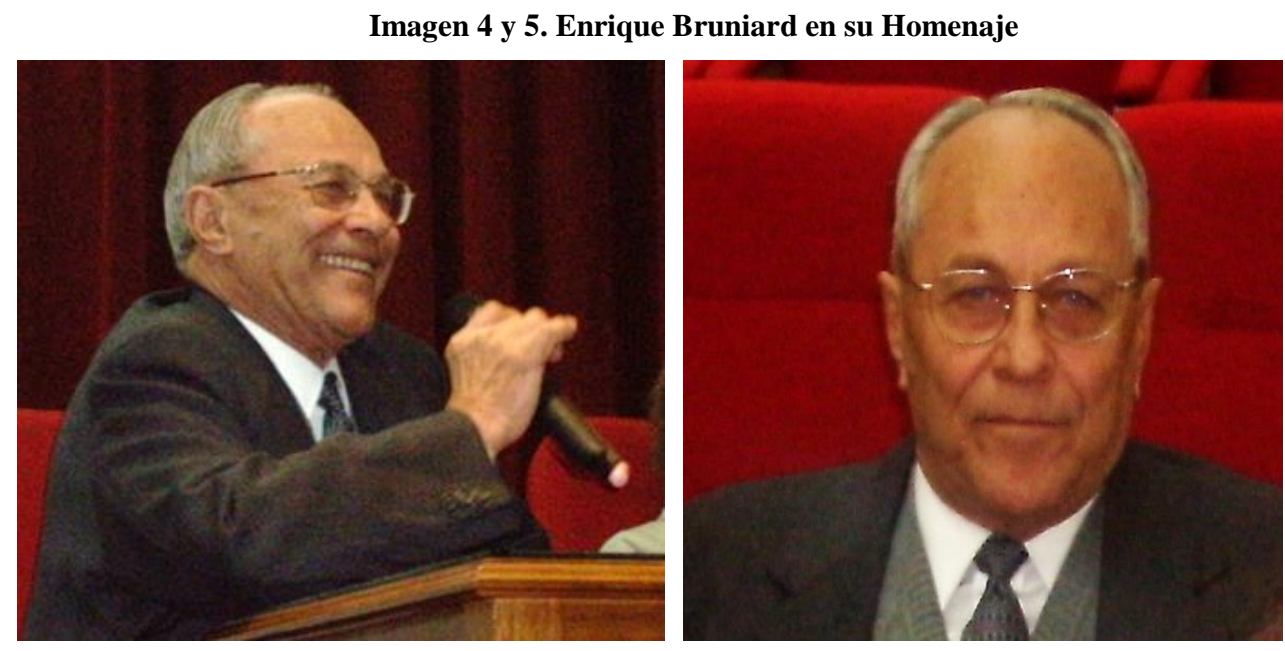

El 1 de abril de 1960 el Dr. Bruniard había iniciado su trayectoria en la Facultad de Humanidades, el 30 de abril de 2010 fue su último día de trabajo. En mi condición de Secretaria Académica, tuve que firmar la Resolución 496/10-D a través de la cual aceptaba su renuncia y se le daba de baja definitiva del plantel docente. Fue doloroso y triste firmar esa Resolución, pero se me dibujó una sonrisa porque la Facultad de Humanidades de la UNNE pudo contar con su valiosa dedicación durante 50 años.

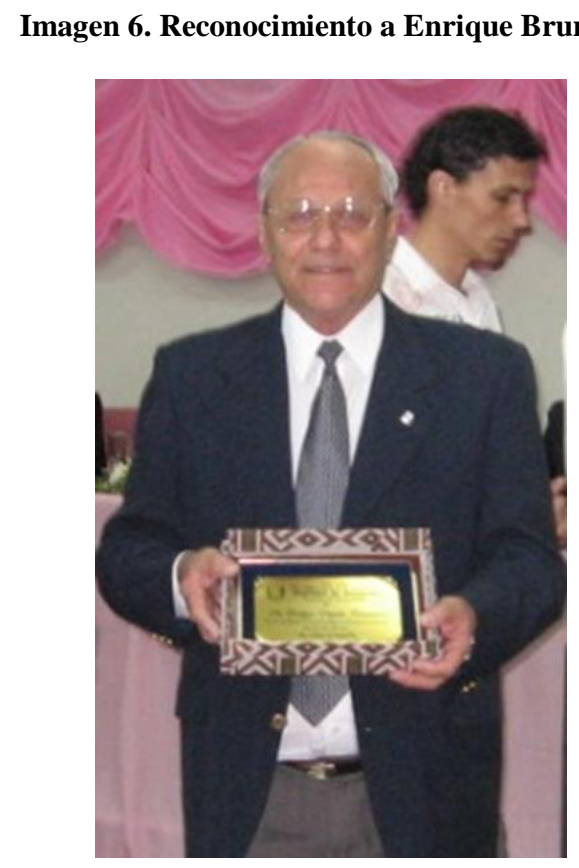

El 15 de noviembre con su desaparición física se cerró una parte importante de la historia del Instituto de Geografía, su paso no ha sido en vano, ni para la Institución ni para ninguno de los que lo hemos conocido.

Gracias Profe. Gracias Doctor. 